\title{
The size of retrieved lymph nodes correlates with the number of retrieved lymph nodes and is an independent prognostic factor in patients with stage II colon cancer
}

\author{
Kazutake Okada $^{1} \cdot$ Sotaro Sadahiro $^{1} \cdot$ Toshiyuki Suzuki $^{1} \cdot$ Akira Tanaka $^{1}$ • \\ Gota Saito $^{1} \cdot$ Shinobu Masuda ${ }^{2}$. Yasuo Haruki ${ }^{3}$
}

Accepted: 2 August 2015 / Published online: 12 August 2015

(C) The Author(s) 2015. This article is published with open access at Springerlink.com

\begin{abstract}
Purpose In stage II colon cancer, patients with many retrieved lymph nodes (LNs) have been reported to have better oncological outcomes. We tested the hypothesis that the greater number of retrieved LNs is related to a larger LN size.

Methods The subjects comprised 320 patients with stage II colon cancer who underwent curative resection. All operations were elective and were performed by the same surgeons. The maximum long axis and short axis diameters of LNs were measured on hematoxylin-eosin-stained specimens.

Results A total of 4,744 LNs were evaluated. The number of retrieved LNs was $14.8 \pm 10.1$ (mean $\pm \mathrm{SD})$. The long axis diameter was $4.8 \pm 2.6 \mathrm{~mm}$, with a median value of $4.3 \mathrm{~mm}$, a maximum value of $20.4 \mathrm{~mm}$, and a minimum value of $0.6 \mathrm{~mm}$. The corresponding short axis diameters were $3.4 \pm$ $1.7,3.0,15.1$, and $0.5 \mathrm{~mm}$, respectively. The highest correlation coefficient for the association with the number of LNs was obtained for the maximum value of the long axis diameter (0.59). Multivariate analysis revealed that age, tumor location, pathological $\mathrm{T}$ stage, and the maximum long axis diameter were independent prognostic factors. The number of LNs was not a significant factor. Patients with less than 12 LNs and a maximum long axis diameter of less than $10 \mathrm{~mm}$ had significantly poorer outcomes $(p<0.001)$.
\end{abstract}

Sotaro Sadahiro

sadahiro@is.icc.u-tokai.ac.jp

1 Department of Surgery, Tokai University, 143 Shimokasuya Isehara, Kanagawa 259-1193, Japan

2 Department of Pathology, Nihon University, Tokyo, Japan

3 Department of Basic Medical Science, Tokai University, Isehara, Japan
Conclusion In patients with stage II colon cancer, the maximum long axis diameter of LNs correlated with the number of LNs and was an independent prognostic factor.

Keywords Colonic neoplasm $\cdot$ Adenocarcinoma $\cdot$ Lymph nodes $\cdot$ Survival analysis $\cdot$ Retrospective study

\section{Introduction}

Low numbers of retrieved lymph nodes (LNs) have been linked to poor outcomes in patients with stage II or III colon cancer [1-7]. The Working Party Report to the World Congress of Gastroenterology in Sydney in 1990 recommended that at least $12 \mathrm{LNs}$ are examined to ensure accurate staging of disease [8]. Inadequately sampled LNs are a high risk factor in stage II colon cancer, and several guidelines have recommended that postoperative adjuvant chemotherapy should be considered in such patients $[9,10]$.

In Japan, LNs are collected by surgeons immediately after surgery. LNs are macroscopically examined and removed from the resected mesentery, fixed in formalin, and submitted for histopathological examination. Even if the extent of LN dissection is similar, the number of retrieved LNs differs among patients. We frequently encounter patients with large LNs that can be easily identified and recovered, as well as those with small LNs that are difficult to find even on careful examination. The present study was performed to test the hypothesis that a greater number of retrieved LNs are related to a larger LN size. We also examined factors influencing the number of retrieved LNs and outcomes in patients with stage II colon cancer. 


\section{Patients and methods}

\section{Patients}

Among patients who underwent elective radical surgery in Tokai University Hospital from January 1991 through December 2003, we studied 320 patients with pathological stage II colon cancer. Patients who underwent emergency surgery were excluded from the present study. The median followup time for living patients was 9.8 years (range, 8.3 to 11.6). This is a retrospective chart review of a prospectively maintained database.

\section{Surgery}

All operations were performed by four or five staff members consisting of two or three colorectal staff surgeons (SS, TS, AT, KO, or GS) and one or two members of the surgical team. All procedures were open surgery, and no patient underwent laparoscopic surgery. All pericolic nodes, intermediate nodes, and main nodes were dissected [11]. LN dissection was distally extended to the bifurcation of the ileocolic artery or right colic artery (or both) from the superior mesenteric artery in patients with rightsided colon cancer, the bifurcation of the middle colic artery from the superior mesenteric artery in patients with transverse colon cancer, and the bifurcation of the inferior mesenteric artery from the aorta in patients with left-sided colon cancer. Both the distal and proximal resection margins were at least $5 \mathrm{~cm}$ from the tumor margin.

\section{Pathological procedures}

One member of the surgical team pinned the resected specimen to a corkboard and identified the blood vessels. The mesentery was classified into three regions: the pericolic lymph node region, the intermediate lymph node region, and the main lymph node region. The lymph nodes were retrieved from each region and were placed in separate containers and submitted to the pathological department. LNs were identified by direct inspection and manual palpation after closely slicing the mesocolon. Fat clearance methods were not used in any patient. Pathologists examined all specimens considered candidate LNs. LNs fixed in formalin were sliced to obtain the maximal cut surface and were stained with hematoxylin and eosin.

\section{Evaluation of the numbers and sizes of retrieved LNs}

The numbers of retrieved LNs were obtained by reviewing the patients' pathological charts. Pathological slides were prepared with the use of a digital camera, and LN size (longest axis, shortest axis) was measured using a computer digitizer (Adobe Photoshop CS5 ${ }^{\circledR}$, Adobe Systems, San Jose, CA, USA, ImageJ 1.47, National Institutes of Health, Bethesda, MD, USA). The mean, median, maximum, and minimum values of the longest and shortest axis diameters of LNs were calculated for each patient.

\section{Clinicopathological variables examined}

In addition to LN size, we examined the relations of the following clinicopathological factors to the number of retrieved LNs and outcomes: sex, age, tumor location, pathological $\mathrm{T}$ stage, histological type, lymphatic invasion, and venous invasion.

\section{Statistical analyses}

Correlations of the number of retrieved LNs with LN size were evaluated with the use of Pearson correlation coefficients. When examining the relations between the number of retrieved LNs and clinicopathological variables, the number of retrieved LNs was separately analyzed as a continuous variable as well as a categorical variable ( $<12$ vs. $\geq 12$ ). Groups were compared with the use of the Fisher's exact test or the chi-square test for categorical variables and the Mann-Whitney $U$ test or the Kruskal-Wallis test for continuous variables.

Cancer outcomes evaluated included overall survival (OS) at the time of the patient's last follow-up. Cumulative survival rates were calculated by the Kaplan-Meier method, and differences between groups were tested with the use of the log-rank test. To determine the optimal cutoff value of LN size for survival analysis, cutoff values were tentatively set at 2-mm intervals. Patients were then divided into two groups according to the tentative cutoff values: those with LNs smaller than the cutoff value and those with LNs equal to or greater than the cutoff value. Overall survival was then compared between each of the groups. The cutoff value associated with the smallest $p$ value was defined as the optimal cutoff value.

Cox proportional hazards modeling was used to adjust comparisons for the clinicopathological variables described above. The numbers of retrieved LNs and LN size were considered continuous variables.

In all statistical analyses, a two-sided value of $p<0.05$ was considered to indicate statistical significance. Statistical calculations were performed using JMP ver. 11 software (SAS Institute Inc., Cary, NC, USA).

This study was approved by the institutional review board of our university (08R-032). 


\section{Results}

\section{Patients' characteristics}

The patients' characteristics are summarized in Table 1. A total of 320 patients (123 women) were studied. The mean age at the time of surgery was $64.8 \pm 12.2$ years (mean \pm standard deviation). The most common tumor location was the sigmoid colon/rectosigmoid colon (54 \% of patients). Pathological T stage was classified as T3 in $82 \%$ of the patients and T4 in $18 \%$.

\section{Numbers and sizes of retrieved LNs}

A total of 4,744 LNs were evaluated. Table 2 shows the numbers and sizes of retrieved LNs. The mean number of retrieved LNs was $14.8 \pm 10.1$, with a median value of 12.0 . The number of retrieved LNs was less than 12 in 149 patients (47\%) and 12 or more in $171(53 \%)$. The mean long axis diameter of LNs was $4.80 \pm 2.59 \mathrm{~mm}$, with a median value of $4.3 \mathrm{~mm}$, a maximum value of $20.4 \mathrm{~mm}$, and a minimum value of $0.6 \mathrm{~mm}$. The mean short axis diameter of LNs was $3.36 \pm 1.71 \mathrm{~mm}$, with a median value of $3.0 \mathrm{~mm}$, a maximum value of $15.1 \mathrm{~mm}$, and a minimum value of $0.5 \mathrm{~mm}$.

\section{Relation between the number of retrieved LNs and the size of the LNs}

Table 3 shows the relation between the number of retrieved LNs and the size of LNs. The correlation coefficient for the association between the number of retrieved LNs and the long axis diameter of the nodes was 0.23 for the mean long axis diameter, 0.16 for the median value, 0.59 for the maximum value, and -0.29 for the minimum value. The correlation coefficient for the association between the number of retrieved LNs and the short axis diameter of the nodes was 0.18 for the mean value, 0.13 for the median value, 0.54 for the maximum value, and -0.33 for the minimum value. For both the long axis and short axis diameters, the highest absolute correlation coefficients for the association with the number of retrieved nodes were obtained for the maximum values, indicating a moderately positive correlation.

As the number of retrieved LNs increased, the maximum long axis diameter became greater, the minimum long axis diameter became smaller, and the dispersion of the values increased. The mean and median diameters of LNs showed virtually no correlation with the number of retrieved LNs (Fig. 1). On the basis of these results, the maximum long axis diameter was used as a representative value of $\mathrm{LN}$ size.

Table 1 Patient's characteristics $(n=320)$

\begin{tabular}{ll}
\hline Variable & $n(\%)$ \\
\hline Sex & \\
Male & $197(62)$ \\
Female & $123(38)$ \\
Age & \\
Mean \pm SD & $64.8 \pm 12.2$ \\
Quartiles & $57,66,74$ \\
Location of the tumor & \\
Cecum & $32(10)$ \\
Ascending colon & $54(17)$ \\
Transverse colon & $42(13)$ \\
Descending colon & $19(6)$ \\
Sigmoid colon/rectosigmoid colon & $173(54)$ \\
Pathological T stage & \\
T3 & $263(82)$ \\
T4 & $57(18)$ \\
Histological type & \\
Well & $185(58)$ \\
Moderate & $116(36)$ \\
Poor & $19(6)$ \\
Lymphatic invasion & \\
Positive & $261(82)$ \\
Negative & $59(18)$ \\
Ponous invasion & \\
Negative & $226(71)$ \\
\hline
\end{tabular}

Well well-differentiated adenocarcinoma, Moderate moderately differentiated adenocarcinoma, Poor poorly differentiated adenocarcinoma

Table 2 Numbers and sizes of retrieved lymph nodes (320 patients)

\begin{tabular}{ll}
\hline Number of retrieved LNs & \\
\hline Mean \pm SD & $14.8 \pm 10.1$ \\
Quartiles & $8.0,12.0,20.0$ \\
$<12$ nodes & $149(47 \%)$ \\
$\geq 12$ modes & $171(53 \%)$ \\
Long axis (mm) $(n=4,744)$ \\
Mean \pm SD & $4.80 \pm 2.59$ \\
Quartiles & $3.0,4.3,6.0$ \\
Maximum & 20.4 \\
Minimum & 0.6 \\
Short axis $(\mathrm{mm})(n=4,744)$ \\
Mean \pm SD & $3.36 \pm 1.71$ \\
Quartiles & $2.1,3.0,4.3$ \\
Maximum & 15.1 \\
Minimum & 0.5
\end{tabular}


Table 3 Relation between the number of retrieved lymph nodes and the size of the nodes

\begin{tabular}{|c|c|c|c|c|c|c|c|c|c|}
\hline & & \multicolumn{4}{|c|}{ Long axis } & \multicolumn{4}{|c|}{ Short axis } \\
\hline & & Mean & Median & Maximum & Minimum & Mean & Median & Maximum & Minimum \\
\hline \multirow[t]{2}{*}{ Number of retrieved LNs } & $r$ & 0.23 & 0.16 & 0.59 & -0.29 & 0.18 & 0.13 & 0.54 & -0.33 \\
\hline & $p$ value & $<0.01$ & $<0.01$ & $<0.01$ & $<0.01$ & $<0.01$ & 0.02 & $<0.01$ & $<0.01$ \\
\hline
\end{tabular}

$r$ Pearson's correlation coefficient

\section{Number of retrieved LNs according to selected variables}

Table 4 shows the relations between clinicopathological factors and the number of retrieved LNs. An age of younger than 65 years and tumors located in the cecum or ascending colon were significantly associated with a greater number of retrieved LNs and a higher proportion of patients with 12 or more retrieved LNs. When the maximum long axis diameter of LNs was classified at 5-mm intervals, an incremental increase in the maximum long axis diameter was accompanied by a stepwise increase in the number of LNs and the proportion of patients with 12 or more retrieved LNs.

\section{Overall survival according to the number of $\mathrm{LNs}$ and the maximum long axis diameter of LNs}

In patients with 12 or more retrieved LNs, the overall survival rate was $84 \%$ at 5 years and $76 \%$ at 8 years, which was significantly better than the corresponding rates in patients with less than 12 retrieved LNs ( $p=0.004)$ (Fig. 2).

The optimal cutoff value for the maximum long axis diameter of LNs was set at $10 \mathrm{~mm}$ because the $p$ value was smallest (Table 5). This value was used for analysis. Patients in whom the maximum long axis diameter of LNs was more than $10 \mathrm{~mm}$ had a 5-year survival rate of $84 \%$ and showed a trend toward better outcomes than those in whom the maximum long axis diameter of LNs was less than $10 \mathrm{~mm}(74 \%$; $p=$ 0.055) (Table 5).

The patients were divided into four groups according to two factors: whether the number of retrieved LNs was $<12$ or $\geq 12$ and whether the maximum long axis diameter was $<10$ or $\geq 10 \mathrm{~mm}$. Overall survival was compared among the four groups (Fig. 3). Patients with $<12$ retrieved LNs and a maximum long axis diameter of $<10 \mathrm{~mm}$ had significantly poorer outcomes, with an overall survival rate of $68 \%$ at 5 years and $58 \%$ at 8 years $(p<0.001)$. Although the number of patients was small $(n=19)$, patients who had $<12$ retrieved LNs and a maximum
Fig. 1 Relation between the number of retrieved lymph nodes and the long axis. The numbers of retrieved lymph nodes are plotted against the mean, median, maximum, and minimum long axis diameters of the lymph nodes (scatter plot). The straight lines are linear regression lines showing the relations between each variable and the number of retrieved lymph nodes

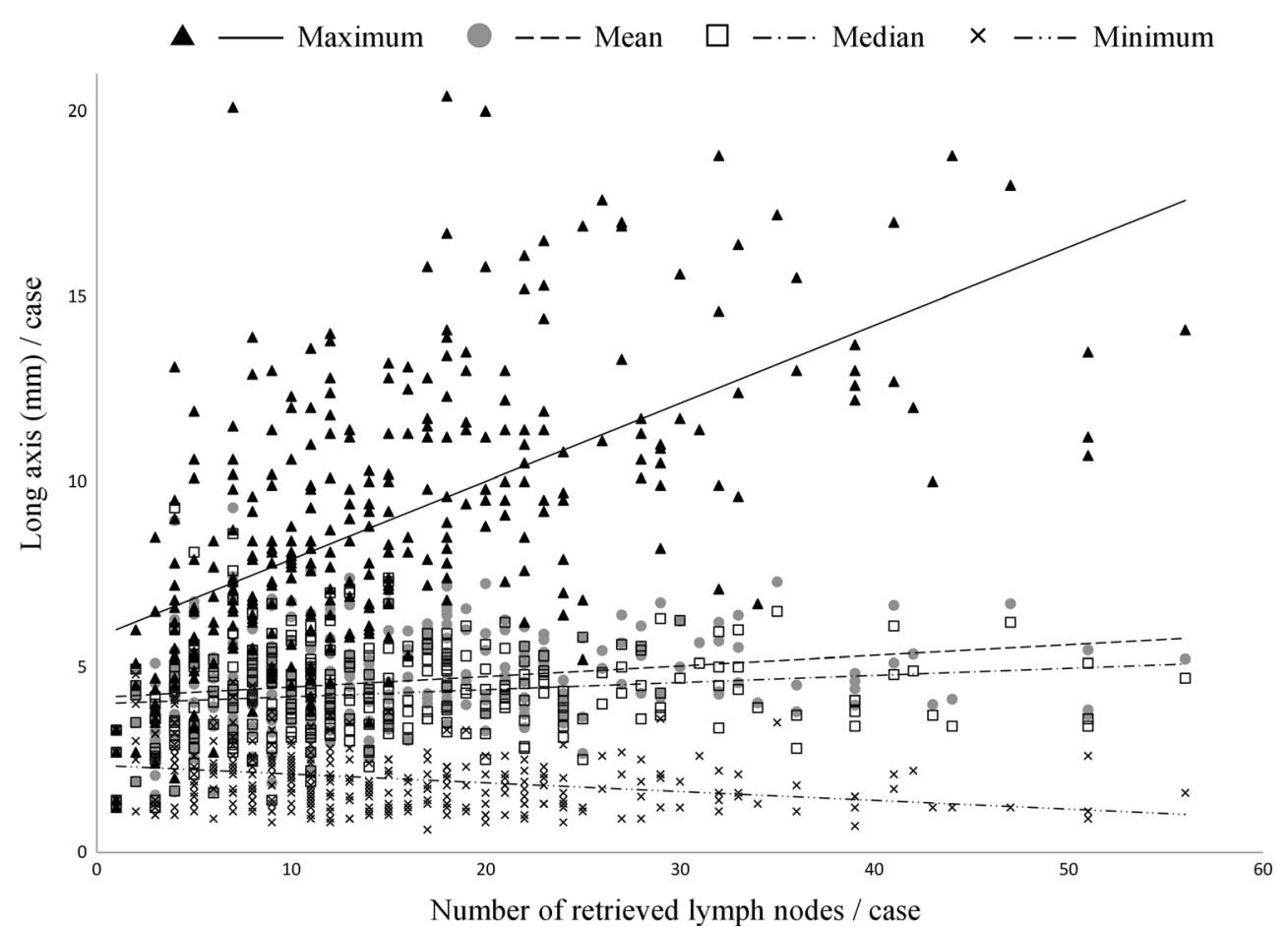


Table 4 Number of retrieved lymph nodes by selected variables (320 patients)

\begin{tabular}{|c|c|c|c|c|}
\hline Variable & $\begin{array}{l}\text { Number of retrieved LNs } \\
\text { Mean } \pm \text { SD }\end{array}$ & $p$ value & $\begin{array}{l}\text { Patients with } \geq 12 \\
\text { LNs total } 171 \\
(53 \%)\end{array}$ & $p$ value \\
\hline \multicolumn{5}{|l|}{ Sex } \\
\hline Men & $14.5 \pm 10.1$ & \multirow[t]{2}{*}{$0.500^{\mathrm{a}}$} & $100 / 197(51)$ & \multirow[t]{2}{*}{$0.250^{\mathrm{c}}$} \\
\hline Women & $15.3 \pm 10.3$ & & $71 / 123(58)$ & \\
\hline \multicolumn{5}{|l|}{ Age (year) } \\
\hline$<65$ & $16.8 \pm 10.5$ & \multirow[t]{2}{*}{$<0.001^{\mathrm{a}}$} & $86 / 138(62)$ & \multirow[t]{2}{*}{$0.007^{\mathrm{c}}$} \\
\hline$\geq 65$ & $13.4 \pm 9.6$ & & $85 / 182(47)$ & \\
\hline \multicolumn{5}{|l|}{ Location of the tumor } \\
\hline Cecum & $17.8 \pm 11.2$ & \multirow[t]{5}{*}{$<0.001^{\mathrm{b}}$} & $23 / 32(72)$ & \multirow[t]{5}{*}{$<0.001^{\mathrm{d}}$} \\
\hline Ascending colon & $20.4 \pm 11.1$ & & $43 / 54(80)$ & \\
\hline Transverse colon & $15.9 \pm 11.6$ & & $24 / 42(57)$ & \\
\hline Descending colon & $10.5 \pm 8.9$ & & $5 / 19(26)$ & \\
\hline Sigmoid colon/rectosigmoid colon & $12.7 \pm 8.5$ & & $76 / 173(44)$ & \\
\hline \multicolumn{5}{|l|}{ Pathological T stage } \\
\hline $\mathrm{T} 3$ & $14.8 \pm 10.0$ & \multirow[t]{2}{*}{$0.855^{\mathrm{a}}$} & $140 / 263(53)$ & \multirow[t]{2}{*}{$0.885^{\mathrm{c}}$} \\
\hline $\mathrm{T} 4$ & $14.9 \pm 11.0$ & & $31 / 57(54)$ & \\
\hline \multicolumn{5}{|l|}{ Histologic type } \\
\hline Well & $14.5 \pm 10.2$ & \multirow[t]{3}{*}{$0.542^{\mathrm{b}}$} & $96 / 185(52)$ & \multirow[t]{3}{*}{$0.627^{\mathrm{d}}$} \\
\hline Moderate & $15.4 \pm 10.5$ & & $63 / 116(54)$ & \\
\hline Poor & $15.1 \pm 7.6$ & & $12 / 19(63)$ & \\
\hline \multicolumn{5}{|l|}{ Lymphatic invasion } \\
\hline Positive & $14.5 \pm 10.0$ & \multirow[t]{2}{*}{$0.228^{\mathrm{a}}$} & $136 / 261(52)$ & \multirow[t]{2}{*}{$0.386^{\mathrm{c}}$} \\
\hline Negative & $16.2 \pm 10.9$ & & $35 / 59(59)$ & \\
\hline \multicolumn{5}{|l|}{ Venous invasion } \\
\hline Positive & $14.3 \pm 9.4$ & \multirow[t]{2}{*}{$0.322^{\mathrm{a}}$} & $119 / 226(53)$ & \multirow[t]{2}{*}{$0.713^{\mathrm{c}}$} \\
\hline Negative & $16.2 \pm 11.6$ & & $52 / 94(55)$ & \\
\hline \multicolumn{5}{|c|}{ Maximum long axis diameter of LNs (mm) } \\
\hline$<5.0$ & $5.6 \pm 4.1$ & \multirow[t]{4}{*}{$<0.001^{\mathrm{b}}$} & $3 / 37(8)$ & \multirow[t]{4}{*}{$<0.001^{\mathrm{C}}$} \\
\hline $5.0-9.9$ & $12.2 \pm 6.7$ & & $76 / 172(44)$ & \\
\hline $10.0-14.9$ & $20.8 \pm 11.7$ & & $71 / 89(80)$ & \\
\hline$\geq 15$ & $27.0 \pm 9.6$ & & $21 / 22(95)$ & \\
\hline
\end{tabular}

${ }^{\text {a }}$ Mann-Whitney $U$ test

${ }^{\mathrm{b}}$ Kruskal-Wallis test

${ }^{\mathrm{c}}$ Fisher's exact test

${ }^{\mathrm{d}}$ Chi-square test

long axis diameter of $\geq 10 \mathrm{~mm}$ had an overall survival rate of $84 \%$ at 5 years and $77 \%$ at 8 years, which did not differ from the survival rates of patients with $\geq 12$ retrieved LNs.

\section{Multivariate Cox model of overall survival (Table 6)}

The results obtained using a multivariate Cox model of overall survival are shown in Table 6. The number of retrieved LNs was related to the maximum long axis diameter of LNs. Therefore, these variables were separately evaluated to avoid multicollinearity. Age at the time of surgery, tumor location, pathological $\mathrm{T}$ stage, and the maximum long axis diameter of
LNs were independent prognostic factors. The number of retrieved LNs was not a significant factor. Higher age, cecal tumors, and T4 tumors were associated with poorer overall survival. A greater maximum long axis diameter of LNs was associated with better overall survival. When the number of retrieved LNs was analyzed as a categorical variable, it became an independent predictive factor (data not shown).

\section{Discussion}

Previous studies have reported that the number of retrieved LNs is related to oncological outcomes in patients with 


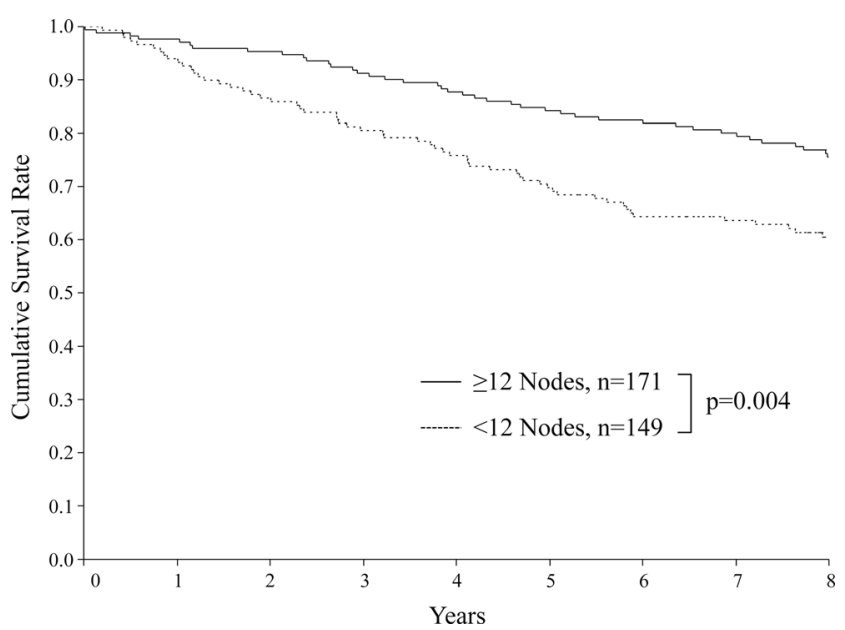

Fig. 2 Overall survival according to number of retrieved lymph nodes

colorectal cancer without distant metastasis [1-7]. The tumornode-metastasis classification of the Union for International Cancer Control (UICC) and the American Joint Committee on Cancer (AJCC) recommends that at least 12 LNs are examined to accurately evaluate $\mathrm{N}$ stage $[12,13]$.

In our study, the overall survival rate was lower in patients with $<12$ retrieved LNs than in those with $\geq 12$ retrieved LNs. However, various cutoff values have been recommended for the number of retrieved LNs required to accurately evaluate $\mathrm{N}$ stage, including 7 or more [14], 8 or more [15], 10 or more [16], 13 or more [4, 17], 14 or more [18], 15 or more [6], 17 or more [1], 18 or more [19,20], and 20 or more [3]. The optimal cutoff value for the number of retrieved LNs thus remains controversial.

In colon cancer, the number of retrieved LNs is influenced by patients' factors, surgical factors, and pathological factors. In previous studies, such factors included the patient's age, year of diagnosis, anatomic site, specimen length, tumor size, pathological $\mathrm{T}$ stage, tumor grade of

Table 5 Kaplan-Meier 5-year overall survival according to maximum long axis diameter of lymph nodes

\begin{tabular}{lllll}
\hline $\begin{array}{l}\text { Cutoff value } \\
(\mathrm{mm})\end{array}$ & $\begin{array}{l}\text { Maximum long axis } \\
\text { diameter of LNs (mm) }\end{array}$ & $n$ & $\begin{array}{l}5 \text {-year OS } \\
\%\end{array}$ & $p^{\mathrm{a}}$ \\
\hline 6 & $<6$ & 65 & 74 & 0.607 \\
& $\geq 6$ & 255 & 78 & \\
8 & $<8$ & 148 & 74 & 0.132 \\
& $\geq 8$ & 172 & 81 & \\
10 & $<10$ & 209 & 74 & 0.055 \\
12 & $\geq 10$ & 111 & 84 & \\
& $<12$ & 260 & 76 & 0.488 \\
14 & $\geq 12$ & 60 & 83 & \\
& $<14$ & 293 & 77 & 0.367 \\
& $\geq 14$ & 27 & 85 & \\
\hline
\end{tabular}

${ }^{\mathrm{a}}$ Log-rank test

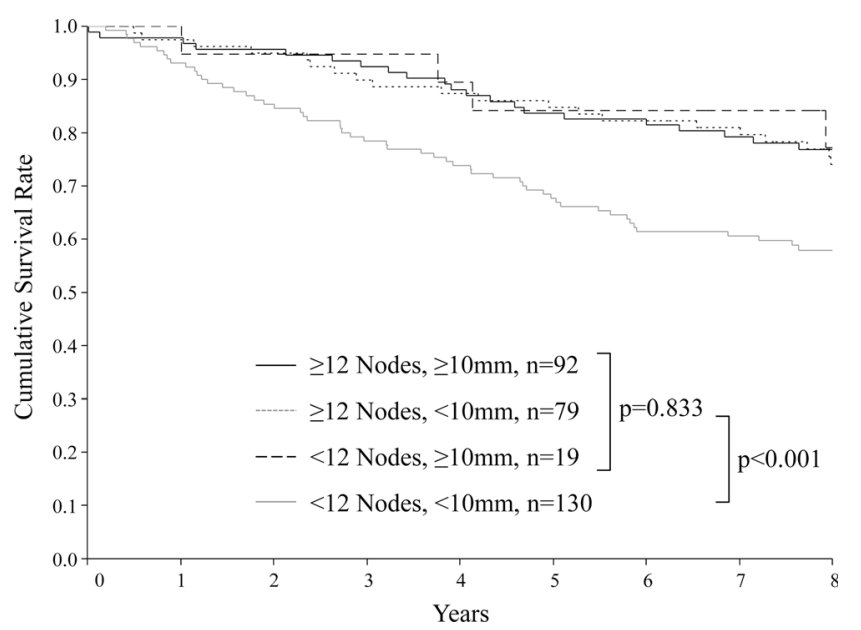

Fig. 3 Overall survival according to number of lymph nodes and maximum long axis diameter of lymph nodes

differentiation, LN status, and surgeon [21-23]. In our study, the number of retrieved LNs was influenced by age, tumor location, and the maximum long axis diameter of the retrieved nodes.

The lower number of LNs in elderly patients has been attributed to the smaller range of LN dissection in elderly patients than in younger adults and the age-related regression of LNs [24-26]. The higher number of LNs retrieved in rightsided colon cancer than in left-sided colon cancer has been ascribed to the proliferation of lymphatic tissue around the ileocecal region and the longer resected length of the right side of the colon than the left side [27]. The length of the resected bowel might affect the number of retrieved LNs. West et al. reported that the lengths of the resected colon in Germany were significantly longer than those in Japan, even if the tumor location was right-sided, transverse, or left-sided. In addition, the number of retrieved LNs was significantly greater in Germany than in Japan [28]. Therefore, in the future, the appropriate number of retrieved lymph nodes might be determined on the basis of patients' age, sex, resected site, and length of the resected bowel.

Few studies have evaluated the relation between the number of retrieved LNs and LN size. Sloothaan et al. reported recently that the median value of $\mathrm{LN}$ size is associated with the number of retrieved LNs in patients without LN metastasis [29]. Markl et al. reported that the total long axis diameter of retrieved LNs correlates with the number of retrieved LNs [30]. In general, however, the sum of the long axis diameter increases in parallel to the number of retrieved nodes. In the present study, the number of retrieved LNs positively correlated with the maximum long axis diameter of LNs. The reason why the mean and median long axis diameters of LNs did not correlate with the number of retrieved LNs may be that the numbers of small as well as large LNs increased with a greater number of retrieved LNs, leading to a greater dispersion of LN size (Fig. 1). 
Table 6 Multivariable Cox model for overall survival

\begin{tabular}{lllllll}
\hline Characteristic & HR & $95 \%$ CI & $p$ value & HR & $95 \%$ CI & $p$ value \\
\hline Sex & & & & & & \\
$\quad$ Men & 1.0 & Reference & & 1.0 & Reference & \\
$\quad$ Women & 0.81 & $0.54-1.22$ & 0.315 & 0.86 & $0.57-1.29$ & 0.473 \\
Age (year) & $1.04^{\mathrm{a}}$ & $1.02-1.06$ & $<0.001$ & $1.04^{\mathrm{a}}$ & $1.02-1.06$ & $<0.001$ \\
Location of the tumor & & & & & & \\
$\quad$ Cecum & 2.05 & $1.07-3.69$ & 0.030 & 2.42 & $1.24-4.48$ & 0.011 \\
$\quad$ Ascending colon & 1.46 & $0.82-2.53$ & 0.199 & 1.41 & $0.81-2.37$ & 0.218 \\
$\quad$ Transverse colon & 1.39 & $0.73-2.47$ & 0.296 & 1.36 & $0.72-2.42$ & 0.323 \\
$\quad$ Descending colon & 0.90 & $0.34-2.00$ & 0.812 & 0.86 & $0.32-1.91$ & 0.729 \\
$\quad$ Sigmoid colon/rectosigmoid colon & 1.0 & Reference & & 1.0 & Reference & \\
Pathological T stage & & & & & & \\
$\quad$ T3 & 1.0 & Reference & & 1.0 & Reference & \\
$\quad$ T4 & 3.30 & $2.12-5.04$ & $<0.001$ & 3.59 & $2.29-5.54$ & $<0.001$ \\
Histological type & & & & & & \\
$\quad$ Well & 1.0 & Reference & & 1.0 & Reference & \\
$\quad$ Moderate & 1.00 & $0.66-1.49$ & 0.986 & 0.97 & $0.65-1.46$ & 0.894 \\
$\quad$ Poor & 0.55 & $0.16-1.36$ & 0.214 & 0.58 & $0.17-1.43$ & 0.259 \\
Lymphatic invasion & & & & & & \\
$\quad$ Positive & 1.0 & Reference & & 1.0 & Reference & \\
$\quad$ Negative & 0.76 & $0.47-1.19$ & 0.237 & 0.73 & $0.45-1.14$ & 0.169 \\
Venous invasion & $0.98^{\mathrm{b}}$ & $0.96-1.00$ & 0.118 & & & \\
$\quad \begin{array}{l}\text { Positive } \\
\text { Negative }\end{array}$ & & & & $0.93^{\mathrm{c}}$ & $0.88-0.99$ & 0.021 \\
Number of retrieved LNs & & & & & & \\
Maximum long axis diameter of LNs (mm) & & & & & & \\
\hline
\end{tabular}

${ }^{\text {a }}$ Estimates the ratio of a 1-year incremental increase in age

${ }^{b}$ Estimates the ratio of a one-node incremental increase in the number of LNs

${ }^{\mathrm{c}}$ Estimates the ratio of a 1-mm incremental increase in lymph node size
The association between few retrieved LNs and poor outcomes has been suggested to be related to understaging and tumor immunity $[5,14]$. LN metastases have been detected even in small LNs less than $5 \mathrm{~mm}$ in diameter [30-35]. Because outcomes are unaffected by the size of metastatic LNs [36], it is important to examine even small LNs 1 to $2 \mathrm{~mm}$ in diameter [1]. However, the risk of tumor understaging caused by overlooking small LNs less than $3 \mathrm{~mm}$ in diameter and less than $5 \mathrm{~mm}$ in diameter has been estimated to be $1.3 \%$ [29] and 2 to $5 \%$ [30], respectively. This value is considered too small to account for the fact that a low number of retrieved LNs (i.e., understaging) is associated with poor outcomes. Factors other than staging accuracy may account for the improvement in survival associated with increased numbers of LNs evaluated in patients with colon cancer [7].

The relation between tumor immunity and the number of retrieved LNs remains unclear. In colorectal cancer, high numbers of tumor-infiltrating lymphocytes are associated with increased numbers of retrieved LNs [37], as well as with better outcomes [38-42]. However, few studies have evaluated the relation between the size of retrieved LNs and outcomes.

The shrinkage rate of lymph nodes after fixation in formalin and staining with hematoxylin-eosin has been reported to be 10 to $16 \%$ regardless of metastases [43, 44]. Therefore, $10 \mathrm{~mm}$ on hematoxylin-eosin-stained pathological slides corresponds to 11 to $12 \mathrm{~mm}$ in vivo.

Murphy et al. reported that patients in whom the mean long axis diameter of retrieved LNs was $<4 \mathrm{~mm}$ had poorer outcomes than those in whom the mean long axis diameter was $\geq 4 \mathrm{~mm}$ [26]. Märkl et al. reported that the retrieval of seven or more LNs with a long axis diameter of $\geq 5 \mathrm{~mm}$ was associated with better outcomes than the retrieval of less than seven LNs of the same size in patients with stage I or II colon cancer [30]. In our study, when the number of retrieved LNs was less than 12 , a maximum long axis diameter of $<10 \mathrm{~mm}$ for the retrieved nodes was associated with poor outcomes. In patients with a maximum long axis diameter of $\geq 10 \mathrm{~mm}$, outcomes were better, regardless of the number of retrieved LNs. 
Apart from tumor metastasis, an increase in LN size can be caused by hyperplasia of cellular components in LNs [45]. In colon cancer, follicular hyperplasia can occur in enlarged regional LNs without metastasis [30]. Therefore, in stage II colon cancer without LN metastasis, the size of regional LNs may reflect the immune status of patients and cancerspecific immune responses [5, 21, 26, 30, 46, 47].

Our results showed that the maximum long axis diameter of LNs was an independent prognostic factor in patients with stage II colon cancer unaccompanied by LN metastasis. A larger maximum long axis diameter of LNs was associated with better outcomes, regardless of the number of retrieved LNs. Although the number of retrieved LNs is influenced by the length of the resected intestine and the extent of dissection, the maximum long axis diameter of LNs is unlikely to be affected by these factors.

In conclusion, the maximum long axis diameter of retrieved LNs correlated with the number of retrieved LNs and was an independent prognostic factor in patients with stage II colon cancer. A prospective multicenter trial is needed to confirm the clinical significance of these variables as predictors of oncological outcomes.

Open Access This article is distributed under the terms of the Creative Commons Attribution 4.0 International License (http:// creativecommons.org/licenses/by/4.0/), which permits unrestricted use, distribution, and reproduction in any medium, provided you give appropriate credit to the original author(s) and the source, provide a link to the Creative Commons license, and indicate if changes were made.

\section{References}

1. Goldstein NS (2002) Lymph node recoveries from 2427 pT3 colorectal resection specimens spanning 45 years: recommendations for a minimum number of recovered lymph nodes based on predictive probabilities. Am J Surg Pathol 26:179-189

2. Cserni G, Vinh-Hung V, Burzykowski T (2002) Is there a minimum number of lymph nodes that should be histologically assessed for a reliable nodal staging of T3N0M0 colorectal carcinomas? J Surg Oncol 81:63-69

3. Le Voyer TE, Sigurdson ER, Hanlon AL, Mayer RJ, Macdonald JS, Catalano PJ, Haller DG (2003) Colon cancer survival is associated with increasing number of lymph nodes analyzed: a secondary survey of intergroup trial INT-0089. J Clin Oncol 21:2912-2919

4. Swanson RS, Compton CC, Stewart AK, Bland KI (2003) The prognosis of T3N0 colon cancer is dependent on the number of lymph nodes examined. Ann Surg Oncol 10:65-71

5. Sarli L, Bader G, Iusco D, Salvemini C, Mauro DD, Mazzeo A, Regina G, Roncoroni L (2005) Number of lymph nodes examined and prognosis of TNM stage II colorectal cancer. Eur J Cancer 41: 272-279

6. Chen SL, Bilchik AJ (2006) More extensive nodal dissection improves survival for stages I to III of colon cancer: a populationbased study. Ann Surg 244:602-610

7. Chang GJ, Rodriguez-Bigas MA, Skibber JM, Moyer VA (2007) Lymph node evaluation and survival after curative resection of colon cancer: systematic review. J Natl Cancer Inst 99:433-441
8. Fielding LP, Arsenault PA, Chapuis PH, Dent O, Gathright B, Hardcastle JD, Hermanek P, Jass JR, Newland RC (1991) Clinicopathological staging for colorectal cancer: an International Documentation System (IDS) and an International Comprehensive Anatomical Terminology (ICAT). J Gastroenterol Hepatol 6:325344

9. Benson AB 3rd, Schrag D, Somerfield MR, Cohen AM, Figueredo AT, Flynn PJ, Krzyzanowska MK, Maroun J, McAllister P, Van Cutsem E, Brouwers M, Charette M, Haller DG (2004) American Society of Clinical Oncology recommendations on adjuvant chemotherapy for stage II colon cancer. J Clin Oncol 22:3408-3419

10. NCCN Clinical Practice Guidelines in Oncology. Colon cancer. V.3.2014. http://www.nccn.org/professionals/physician_gls/pdf/ colon.pdf. Accessed 25 July 2014

11. Japanese Society for Cancer of the Colon and Rectum (2009) Japanese classification of colorectal carcinoma. 2nd English edition. Kanehara \& Co, Ltd, Tokyo

12. Compton CC, Fielding LP, Burgart LJ, Conley B, Cooper HS, Hamilton SR, Hammond ME, Henson DE, Hutter RV, Nagle RB, Nielsen ML, Sargent DJ, Taylor CR, Welton M, Willett C (2000) Prognostic factors in colorectal cancer. College of American Pathologists consensus statement 1999. Arch Pathol Lab Med 124:979-994

13. Hammond ME, Fitzgibbons PL, Compton CC, Grignon DJ, Page DL, Fielding LP, Bostwick D, Pajak TF (2000) College of American Pathologists Conference XXXV: solid tumor prognostic factors - which, how and so what? Summary document and recommendations for implementation. Cancer committee and conference participants. Arch Pathol Lab Med 124:958-965

14. Caplin S, Cerottini JP, Bosman FT, Constanda MT, Givel JC (1998) For patients with Dukes' B (TNM stage II) colorectal carcinoma, examination of six or fewer lymph nodes is related to poor prognosis. Cancer 83:666-672

15. Maurel J, Launoy G, Grosclaude P, Gignoux M, Arveux P, Mathieu-Daude H, Raverdy N, Faivre J (1998) Lymph node harvest reporting in patients with carcinoma of the large bowel: a French population-based study. Cancer 82:1482-1486

16. Pocard M, Panis Y, Malassagne B, Nemeth J, Hautefeuille P, Valleur P (1998) Assessing the effectiveness of mesorectal excision in rectal cancer: prognostic value of the number of lymph nodes found in resected specimens. Dis Colon Rectum 41:839-845

17. Johnson PM, Porter GA, Ricciardi R, Baxter NN (2006) Increasing negative lymph node count is independently associated with improved long-term survival in stage IIIB and IIIC colon cancer. J Clin Oncol 24:3570-3575

18. Wong JH, Severino R, Honnebier MB, Tom P, Namiki TS (1999) Number of nodes examined and staging accuracy in colorectal carcinoma. J Clin Oncol 17:2896-2900

19. Joseph NE, Sigurdson ER, Hanlon AL, Wang H, Mayer RJ, MacDonald JS, Catalano PJ, Haller DG (2003) Accuracy of determining nodal negativity in colorectal cancer on the basis of the number of nodes retrieved on resection. Ann Surg Oncol 10:213218

20. Scott KW, Grace RH (1989) Detection of lymph node metastases in colorectal carcinoma before and after fat clearance. Br J Surg 76: $1165-1167$

21. Dillman RO, Aaron K, Heinemann FS, McClure SE (2009) Identification of 12 or more lymph nodes in resected colon cancer specimens as an indicator of quality performance. Cancer 115: $1840-1848$

22. Chou JF, Row D, Gonen M, Liu YH, Schrag D, Weiser MR (2010) Clinical and pathologic factors that predict lymph node yield from surgical specimens in colorectal cancer: a population-based study. Cancer 116:2560-2570

23. Stocchi L, Fazio VW, Lavery I, Hammel J (2011) Individual surgeon, pathologist, and other factors affecting lymph node harvest in 
stage II colon carcinoma. Is a minimum of 12 examined lymph nodes sufficient? Ann Surg Oncol 18:405-412

24. Schmucker DL, Owen RL, Outenreath R, Thoreux K (2003) Basis for the age-related decline in intestinal mucosal immunity. Clin Dev Immunol 10:167-172

25. Edler D, Ohrling K, Hallstrom M, Karlberg M, Ragnhammar P (2007) The number of analyzed lymph nodes - a prognostic factor in colorectal cancer. Acta Oncol 46:975-981

26. Murphy J, Pocard M, Jass JR, O'Sullivan GC, Lee G, Talbot IC (2007) Number and size of lymph nodes recovered from dukes B rectal cancers: correlation with prognosis and histologic antitumor immune response. Dis Colon Rectum 50:1526-1534

27. Kotake K, Honjo S, Sugihara K, Hashiguchi Y, Kato T, Kodaira S, Muto T, Koyama Y (2012) Number of lymph nodes retrieved is an important determinant of survival of patients with stage II and stage III colorectal cancer. Jpn J Clin Oncol 42:29-35

28. West NP, Kobayashi H, Takahashi K, Perrakis A, Weber K, Hohenberger W, Sugihara K, Quirke P (2012) Understanding optimal colonic cancer surgery: comparison of Japanese D3 resection and European complete mesocolic excision with central vascular ligation. J Clin Oncol 30:1763-1769

29. Sloothaak DA, Grewal S, Doornewaard H, van Duijvendijk P, Tanis PJ, Bemelman WA, van der Zaag ES, Buskens CJ (2014) Lymph node size as a predictor of lymphatic staging in colonic cancer. $\mathrm{Br} \mathrm{J}$ Surg 101:701-706

30. Markl B, Rossle J, Arnholdt HM, Schaller T, Krammer I, Cacchi C, Jahnig H, Schenkirsch G, Spatz H, Anthuber M (2012) The clinical significance of lymph node size in colon cancer. Mod Pathol 25: $1413-1422$

31. Herrera L, Villarreal JR (1992) Incidence of metastases from rectal adenocarcinoma in small lymph nodes detected by a clearing technique. Dis Colon Rectum 35:783-788

32. Hida J, Mori N, Kubo R, Matsuda T, Morikawa E, Kitaoka M, Sindoh K, Yasutomi M (1994) Metastases from carcinoma of the colon and rectum detected in small lymph nodes by the clearing method. J Am Coll Surg 178:223-228

33. Bjelovic M, Kalezic V, Petrovic M, Pesko P, Usaj SK, Marinkovic J, Radovanovic N (1998) Correlation of macroscopic and histological characteristics in the regional lymph nodes of patients with rectal and sigmoidal adenocarcinoma. Hepatogastroenterology 45: 433-438

34. Brown HG, Luckasevic TM, Medich DS, Celebrezze JP, Jones SM (2004) Efficacy of manual dissection of lymph nodes in colon cancer resections. Mod Pathol 17:402-406

35. Perez RO, Pereira DD, Proscurshim I, Gama-Rodrigues J, Rawet V, Sao Juliao GP, Kiss D, Cecconello I, Habr-Gama A (2009) Lymph node size in rectal cancer following neoadjuvant chemoradiationcan we rely on radiologic nodal staging after chemoradiation? Dis Colon Rectum 52:1278-1284

36. Rodriguez-Bigas MA, Maamoun S, Weber TK, Penetrante RB, Blumenson LE, Petrelli NJ (1996) Clinical significance of colorectal cancer: metastases in lymph nodes $<5 \mathrm{~mm}$ in size. Ann Surg Oncol 3:124-130

37. Kim YW, Jan KM, Jung DH, Cho MY, Kim NK (2013) Histological inflammatory cell infiltration is associated with the number of lymph nodes retrieved in colorectal cancer. Anticancer Res 33:5143-5150

38. Graham DM, Appelman HD (1990) Crohn's-like lymphoid reaction and colorectal carcinoma: a potential histologic prognosticator. Mod Pathol 3:332-335

39. Naito Y, Saito K, Shiiba K, Ohuchi A, Saigenji K, Nagura H, Ohtani H (1998) CD8+ T cells infiltrated within cancer cell nests as a prognostic factor in human colorectal cancer. Cancer Res 58: 3491-3494

40. Prall F, Duhrkop T, Weirich V, Ostwald C, Lenz P, Nizze H, Barten M (2004) Prognostic role of CD8+ tumor-infiltrating lymphocytes in stage III colorectal cancer with and without microsatellite instability. Hum Pathol 35:808-816

41. George S, Primrose J, Talbot R, Smith J, Mullee M, Bailey D, du Boulay C, Jordan H (2006) Will Rogers revisited: prospective observational study of survival of 3592 patients with colorectal cancer according to number of nodes examined by pathologists. Br J Cancer 95:841-847

42. Pages F, Galon J, Dieu-Nosjean MC, Tartour E, Sautes-Fridman C, Fridman WH (2010) Immune infiltration in human tumors: a prognostic factor that should not be ignored. Oncogene 29:1093-1102

43. Monig SP, Baldus SE, Zirbes TK, Schroder W, Lindemann DG, Dienes HP, Holscher AH (1999) Lymph node size and metastatic infiltration in colon cancer. Ann Surg Oncol 6:579-581

44. Noda N, Sasako M, Yamaguchi N, Nakanishi Y (1998) Ignoring small lymph nodes can be a major cause of staging error in gastric cancer. Br J Surg 85:831-834

45. Weiss LM, O'Malley D (2013) Benign lymphadenopathies. Mod Pathol 26:S88-S96

46. Wong SL, Ji H, Hollenbeck BK, Morris AM, Baser O, Birkmeyer JD (2007) Hospital lymph node examination rates and survival after resection for colon cancer. JAMA 298:2149-2154

47. Vather R, Sammour T, Kahokehr A, Connolly AB, Hill AG (2009) Lymph node evaluation and long-term survival in stage II and stage III colon cancer: a national study. Ann Surg Oncol 16:585-593 